\title{
Synthesis and Electrochemical Characterization a Coating of $\beta$-Tricalcium Phosphate Deposited on Steel 316LVM
}

\author{
W. Aperador ${ }^{*}$, J. Duque, E. Delgado \\ School of Engineering, Universidad Militar Nueva Granada, Bogotá-Colombia \\ *E-mail: g.ing.materiales@gmail.com
}

doi: $10.20964 / 110402945$

Received: 19 January 2016 / Accepted: 8 February 2016 / Published: 1 March 2016

\begin{abstract}
Beta tricalcium phosphate thin films they were deposited on austenitic steel by means of a magnetron sputtering with r.f. (13.56 MHz) from tricalcium phosphate (TCP) which it was used as a sputtering target. In order to study the effect of the content of the coating; in the corrosion rate and electrochemical response function of time $(0,24,196$ and 720 hours) of the coated steels, corrosion rate is studied by polarization curves Tafel and the electrochemical response by electrochemical impedance spectroscopy, microstructural characterization was performed using scanning electron microscopy (SEM). Finding himself a decrease of $32 \%$ in the corrosion rate for the system evaluated to 720 hours. The ion exchange capacity indicates an increase in corrosion resistance.
\end{abstract}

Keywords: tricalcium phosphate; Physical vapor deposition; Corrosion; Biomaterials

\section{$\underline{\text { FULL TEXT }}$}

(C) 2016 The Authors. Published by ESG (www.electrochemsci.org). This article is an open access article distributed under the terms and conditions of the Creative Commons Attribution license (http://creativecommons.org/licenses/by/4.0/). 